\title{
Solvent effect on the absorption and emission spectra of carbon dots: evaluation of ground and excited state dipole moment
}

\author{
Parisa Mohammad-Jafarieh ${ }^{1}$, Abolfazl Akbarzadeh ${ }^{2,5^{*}}$, Rahman Salamat-Ahangari ${ }^{1}$, \\ Mohammad Pourhassan-Moghaddam ${ }^{3}$ and Kazem Jamshidi-Ghaleh ${ }^{4}$
}

\begin{abstract}
Background: Carbon dots (C-dots) are photoluminescent nanoparticles with less than $10 \mathrm{~nm}$ in size. Today, many studies are performed to exploit the photoluminescence $(\mathrm{PL})$ property of carbon dots, and our focus in this study is to estimate the dipole moment of carbon dots. For reaching our aims, C-dots were synthesized and dissolved in the different solvents.

Results: Carbon dots with intense photoluminescence properties have been synthesized by a one-step hydrothermal method from a carbon bio-source. In this research, we report on the effect of aprotic solvents on absorption and fluorescence spectra and dipole moments of C-dots dispersed in a range of many aprotic solvents with various polarity and dielectric constant at room temperature. The change in the value of dipole moment was estimated by using the Stokes shifts. The difference between the dipole moment of the excited state and the ground state was shown using an extended form of Lippert equations by Kawski and co-workers.

Conclusions: The values found for $\mu_{g}=1.077 \mathrm{D}$, and $\mu_{\mathrm{e}}=3.157 \mathrm{D}$, as well as the change in the dipole moments. The results showed that the dipole moment of the excited state is more than the ground state, indicating a high density and redistribution of electrons in the excited state. Finally, the quantum yield of C-dots in the eclectic aprotic solvents was communicated and discussed.
\end{abstract}

Keywords: Carbon dots, Photoluminescence, Dipole moment, Quantum yield, KAT parameters, Solvatochromic

\section{Introduction}

Carbon-based nanomaterials such as carbon nanotubes, fullerene and graphene have poor solubility in water and lack strong fluorescence in the visible area, limiting their applications [1]. These shortcomings can be addressed by carbon dots (C-dots) which are spherical carbon-based nanoparticles with a size of less than $10 \mathrm{~nm}$ [2]. C-dots are heavily fluorescent, non-blinking, water soluble, chemically stable and can be easily synthesized

\footnotetext{
*Correspondence: dr.akbarzadeh2010@gmail.com

${ }^{5}$ Department of Medical Nanotechnology, Faculty of Medical Sciences,

Tabriz University of Medical Sciences, Tabriz, Iran

Full list of author information is available at the end of the article
}

at low cost $[3,4]$. Also, introduction of full-color fluorescent $\mathrm{C}$-dots [5] is another advantage that can expand their application spectrum. C-dots was first discovered by electrophoretic purification of single-walled carbon nanotubes in 2004 [6]. In recent years, different materials and synthesis methods have been used to obtain C-dots. The synthesis approaches of C-dots can be classified into two categories: top-down and bottom-up methods including hydrothermal $[7,8]$, electrochemical oxidation [9], acidic oxidation [10], microwave [11, 12], and laser ablation [13].

Owing to their physicochemical properties, C-dots can take part in the chemiluminescence reaction as oxidants, 
emitting species, energy acceptors of chemical reaction energy or even as catalyst involving in different chemiluminescence systems $[14,15]$. For the first time, Shen and et al. fabricated chemiluminescence $\mathrm{C}$-dots and used it to develop new class of CL nanosensors for the imaging Reactive oxygen species [16]. Also C-dots have gained widespread attention in recent years, especially in chemical censoring [17], biosensing [18], bioimaging [19], drug delivery [20], solar cells [21], light-emitting diode (LED) [22], and electrocatalysis [23].

C-dots are easily dispersed in protic and aprotic solvents due to carboxyl, hydroxyl, and carbonyl groups. The interaction between $\mathrm{C}$-dots and solvent plays an essential role in the wavelength of photoluminescence emissions. In summary, no single theory can be used for a quantitative explanation of the effects of the environment on fluorescence. Explanation of these effects depends not only on polarity considerations but also on the structure of the $\mathrm{C}$-dots and the types of chemical interactions it can experience with other near molecules. Kumar et al. [24] report on solvent-dependent spectroscopic study of fluorescent carbon nanoparticles in organic solvents. They have found that the absorption spectra of the nanoparticles were independent of solvent nature, while their photoluminescence spectra were considerably dependent on the solvent nature. The trends observed with solvent polarity follow the theory of general solvent effects, which may give the impression that solvent polarity is the only factor to consider. Solvent-solute interaction and the trace of solvent environments are investigated by considering various solvent parameters such as hydrogen bond capability, hydrogen bond acceptability and polarization on dipole moment $[25,26]$. Determining the dipole moment of electron balances is crucial because it can explain how electron distribution changes under excitation. Suppan has shown that the most acceptable method to approximate the excited dipole moment of a solute involves the simultaneous estimation of the absorption and fluorescence spectra of the solute in the range of solvent [27]. C-dot fluorescence properties are complicated by dependence on excitation wavelength [28] and solvent nature $[24,29]$. Because there are functional groups on the $\mathrm{C}$-dots surface, they are therefore available to solvent molecules so that strong interactions of $\mathrm{C}$-dots with solvent molecules can have a significant effect on fluorescence. We use the solvatochromic method in which the amount of polarity of the base and dipole moment was calculated, followed by the investigation of their differences in a variety of aprotic solvents.

Different methods [28, 30-34] have been introduced for solvatochromic measurement of the dipole moment.

Pursuing our previous work on protic solvents [35], we aim to understand the effect of intermolecular interactions of synthesized $\mathrm{C}$-dots and aprotic solvents. The focus is to study the spectral changes of C-dots in aprotic solvents by using the concept of Kamlet-Abboud-Taft's linear solubility energy. Kamlet-Abboud-Taft's equation is one of the most reliable methods of measuring solvent effects on dissolved $\mathrm{C}$-dots. This equation applies the solvent polarity parameter result on the solute's spectral features [36].

\section{Experimental \\ Materials}

C-dots were synthesized by hydrothermal treatment of persimmon peel. All the solvents used in this research were of the highest degree of purity available from Merck. The physical properties and polarity functions of the solvents are given in Table 1; Spectroscopic polarity parameters in various aprotic solvents are provided in Table 2.

\section{Synthesis and characterization of C-dots}

The green C-dots synthesis method, their characterization and structures, were thoroughly described in our previous work [38].

Briefly, the C-dots were synthesized from persimmon peels by hydrothermal treatment. In the first step, persimmon was cut into pieces and ground into a mixture. Then, $50 \mathrm{~mL}$ ultrapure water was added, and the solution

Table1 Physical properties, and polarity functions in aprotic solvents

\begin{tabular}{lllllll}
\hline Solvents & $\boldsymbol{\varepsilon}$ & $\mathbf{n}$ & $\boldsymbol{\pi}^{*}$ & $\mathbf{a}$ & $\mathbf{\beta}$ & QY \\
\hline DMSO & 47.24 & 1.47 & 1 & 0 & 0.76 & 0.26 \\
Acetonitrile & 36.64 & 1.34 & 0.75 & 0.19 & 0.4 & 0.12 \\
DMF & 38.25 & 1.43 & 0.88 & 0 & 0.69 & 0.17 \\
DCM & 9.1 & 1.42 & 0.82 & 0.13 & 0.12 \\
Acetic Acid & 6.15 & 1.37 & 0.64 & 0 & 0.45 \\
Diethyl ether & 4.33 & 1.34 & 0.27 & 0 & 0.47 & 0.37 \\
Dioxane & 2.3 & 1.42 & 0.55 & & 0.12 \\
\hline
\end{tabular}


Table 2 Solvent effects on the position of absorption and fluorescence maxima of C-dots: spectroscopic polarity parameters in various aprotic solvents

\begin{tabular}{lllllll}
\hline Solvents & $\left.\mathbf{v}_{\mathbf{a}} \mathbf{( k K}\right)=\mathbf{1 0}_{\mathbf{3}}^{\mathbf{3}} \mathbf{c m}^{-\mathbf{1}}$ & $\mathbf{v}_{\mathbf{f}} \mathbf{( k K )}$ & $\mathbf{v}_{\mathbf{a}}-\mathbf{v}_{\mathbf{f}}$ & $\mathbf{v}_{\mathbf{a}}+\mathbf{v}_{\mathbf{f}}$ & $\mathbf{f}(\boldsymbol{\varepsilon}, \mathbf{n})$ & $\mathbf{f}(\boldsymbol{\varepsilon}, \mathbf{n})+\mathbf{2} \mathbf{g}(\mathbf{n})$ \\
\hline DMSO & 35.77 & 21.92 & 13.84 & 57.70 & 0.841 & 1.660 \\
Acetonitrile & 35.71 & 22.19 & 13.51 & 57.91 & 0.862 & 1.533 \\
DMF & 35.21 & 22.22 & 12.98 & 57.43 & 0.839 & 1.606 \\
DCM & 35.58 & 22.47 & 13.11 & 58.05 & 0.597 & 1.353 \\
Acetic Acid & 35.46 & 22.57 & 12.88 & 58.03 & 0.497 & 1.200 \\
Diethyl ether & 36.49 & 22.72 & 13.76 & 59.22 & 0.382 & 1.054 \\
Dioxane & 35.58 & 22.88 & 12.70 & 58.47 & 0.045 & 0.801 \\
\hline
\end{tabular}

was kept for 15 min under magnetic stirring, and the obtained juice was autoclaved using a Teflon lined stainless steel autoclave reactor at $120^{\circ} \mathrm{C}$ for $150 \mathrm{~min}$. The autoclave was allowed to cool at room temperature, and the resultant dark brown solution was centrifuged at $10,000 \mathrm{rpm}$ for $20 \mathrm{~min}$ to separate the larger particles. In the next step, the $\mathrm{pH}$ of the aqueous solution was adjusted to neutral with $1 \mathrm{M} \mathrm{NaOH}$, and the C-dots solution was filtrated with a $0.22 \mu \mathrm{m}$ filter membrane. In the final step, the C-dots solution was further purified by dialysis against (1000MWCO) deionized water for $24 \mathrm{~h}$. The powder of $\mathrm{C}$-dots was obstinate by lyophilization for $48 \mathrm{~h}$ and stored at $4{ }^{\circ} \mathrm{C}$ until further use. The formation of C-dots with an average size of $2 \mathrm{~nm}$ was obtained. Together with elemental analysis by $\mathrm{CHN}$-analyser and using FE-SEM, the nitrogen and carbonyl-containing functional groups on the surface of C-dots were also revealed by the FTIR method. Accordingly, for further spectroscopic analyses, a $0.1 \%(\mathrm{~W} / \mathrm{V}) \mathrm{C}$-dots solution was prepared in aprotic solvents by mixing for $4 \mathrm{~h}$ to obtain homogenous solutions.

\section{Absorption and emission spectroscopy}

UV-Vis absorption spectra of the C-dot solutions in different aprotic solvents were recorded by a CECIL CE7250 Spectrophotometer with a $1 \mathrm{~cm}$ quartz cuvette at room temperature over a wavelength range of 200-600 nm. Meanwhile, photoluminescence (PL) measurements were undertaken using a Cytation 5/Biotek/USA fluorescence spectrophotometer with excitation slit set at $1 \mathrm{~nm}$ pass and emission at $1 \mathrm{~nm}$ bandpass in 96 cell plates.

\section{Results and discussion}

The theory of universal solvent effects provides beneficial information for consideration of solvent-dependent spectral shifts. In explaining general solvent effects, the $\mathrm{C}$-dots is a dipole in a continuous medium of uniform dielectric constant.
The interactions between the solvent and C-dots affect the energy difference between the ground and excited states and the orientation polarizability of solvents. The dipole moment represents the electron distribution in a molecule with a specific structure. In combination with the reactive field around it, the dipole moment plays an essential role in the transition of a molecule because a molecule can absorb light when its dipolar moment changes.

C-dots' absorption and fluorescence emission spectra in the range of different aprotic solvents with dielectric constant and refractive index were recorded at room temperature.

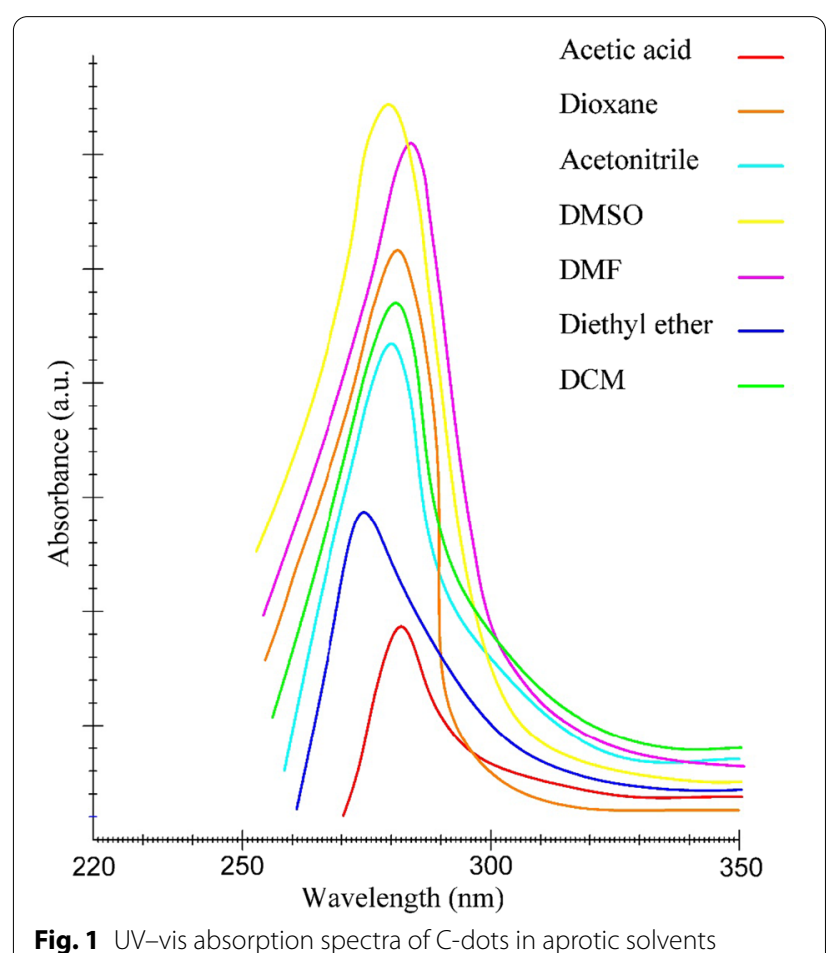




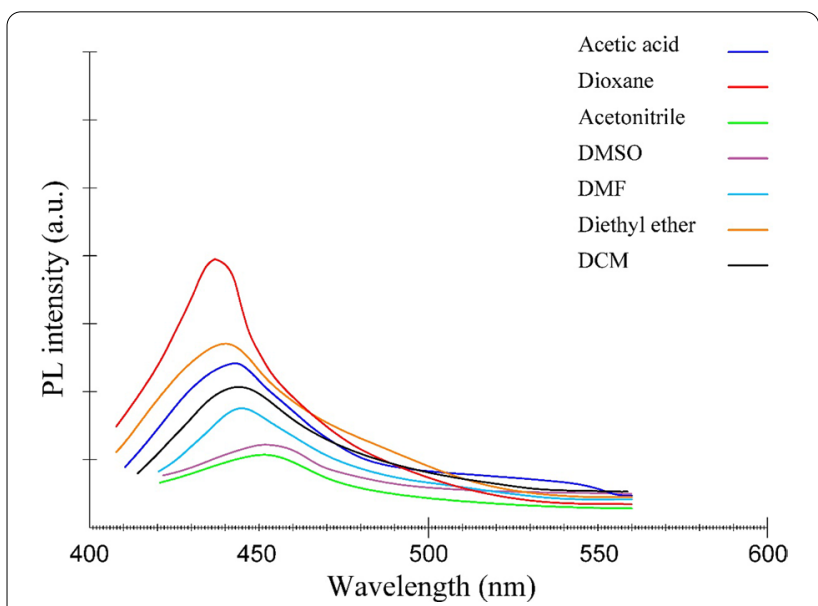

Fig. 2 Florescence spectra of C-dots in aprotic solvents

Depending on the solvent's polarity, the aprotic solvent used in the registration of UV-Vis absorption and emission fluorescence spectra of the C-dots, depending on the solvent's polarity, influenced the positions, intensity, and shape of the solvent-C-dots complex. The UV-vis absorption spectra of the C-dots were observed in the UV region with maximum absorption at 237-256 $\mathrm{nm}$ and a tail extending into the visible range (Fig. 1). This is attributed to the $n-\pi^{*}$ transition of $\mathrm{C}=\mathrm{O}$ band and $\pi-\pi^{*}$ transition of $\mathrm{C}=\mathrm{C}$ band.

The behavioural mechanism of PL is not yet fully understood, and our recent studies in calculating the ground and excited state dipole moment are a step forward in understanding the mechanism of this C-dots effect. One possible reason for the PL behaviour is the presence of different particle sizes of C-dots; and the different distribution of $\mathrm{C}$-dots surface energy traps, the nature of the surface, and the presence of numerous functional groups on the surface of the $\mathrm{C}$-dots may result in a series of emissive traps between $\pi$ and $\pi^{*}$ of $C-C$. [37]. The results obtained from the absorption and fluorescence spectra in Fig. 1 and 2 shows that the displacement observed in the absorption and emission spectra of $\mathrm{C}$-dots indicates the dependence of $\mathrm{C}$-dots on solvent polarity, which means that the change of solvent polarity displacement in the emission spectra is relative to the absorption spectra.

\section{Estimation of the ground state and excited state dipole moments}

In order to approximate the ground state and excited state dipole moments of the C-dots, spectral shifts $\left(\bar{v}_{\mathrm{A}}-\bar{v}_{\mathrm{F}}\right)$ and $\left(\bar{v}_{\mathrm{A}}+\bar{v}_{\mathrm{F}}\right)$ of fluorescence C-dots were calculated along with solvent polarity $\left(v_{\mathrm{A}}\right.$ and $v_{\mathrm{F}}$ are the wavenumbers $\left(\mathrm{cm}^{-1}\right)$ of the absorption and emission).

The result demonstrates that the excited dipole moment is larger during the $\mathrm{C}$-dots electronic transition than the ground dipole moment, i.e. $\mu_{\mathrm{e}}>\mu_{\mathrm{g}}$. Therefore, the dipolar solvent polarisation, the Franck-Condon excited state, is more solvated foremost to the experiential redshift in the spectrum.

To a first estimate, this energy difference $\left(\right.$ in $\mathrm{cm}^{-1}$ ) is a property of the refractive index $(n)$ and dielectric constant $(\varepsilon)$ of the solvent, and is described by the LippertMataga [30, 31] equation as below:

$$
\bar{v}_{\mathrm{A}}-\bar{v}_{\mathrm{F}}=\frac{2}{\mathrm{hc}}\left(\frac{\varepsilon-1}{2 \varepsilon+1}-\frac{\mathrm{n}^{2}-1}{2 \mathrm{n}^{2}+1}\right) \frac{\left(\mu_{\mathrm{e}}-\mu_{\mathrm{g}}\right)^{2}}{\mathrm{a}^{3}}+\text { const }
$$

In this equation $\mathrm{h}=6.6256 \times 10^{-27}$ ergs is Planck's constant, $\mathrm{c}=2.9979 \times 10^{10} \mathrm{~cm} / \mathrm{s}$ is the speed of light, and a is the radius of the cavity in which the fluorophore resides. In this equation, the opposite effects of $v_{\mathrm{A}}$ and $v_{\mathrm{F}}$ on the Stokes shift are significant. As the refractive index (n) increases, this energy difference decreases, whereas an increase in $\varepsilon$ results in a larger difference between $v_{\mathrm{A}}$ and $v_{\mathrm{F}}$. The refractive index is a rapid frequency response that depends on the motion of electrons in solvent molecules that occur when light is absorbed. In contrast with the refractive index, the dielectric constant is a static and steady feature that depends on the electrons and molecular motions of the solvents' organization around the excited state. Increasing the refractive index (n) of the ground and excited states is quickly stabilized by the motion of electrons in solvent molecules. This redistribution of electrons reduces the energy difference between ground and excited states. Lippert-Mataga framework, there is no consideration of specific interaction with solvent. Thus, several investigators attempted to extend and modify the Lippert equation. Kawski and co-workers [38-40] obtained a simple quantum mechanical second-order perturbation theory for absorption $\left(v_{\mathrm{A}}\right)$ and fluorescence $\left(v_{\mathrm{F}}\right)$ band shifts. By variation of $\varepsilon$ and $\mathrm{n}$ in solvents, as explained below, functions $f(\varepsilon, n)$ and $g(n)$ refer to Bakhshiev [41] and Kawski-Chamma-Viallet [33, 34] relations, respectively. Consequentially the solvent dependent changes for the difference and sum of $v_{\mathrm{A}}$ with $v_{\mathrm{F}}$ have been defined by the following equations:

$$
\begin{aligned}
& \bar{v}_{\mathrm{A}}-\bar{v}_{\mathrm{F}}=m_{1} f(\varepsilon n)+\text { const } \\
& \bar{v}_{\mathrm{A}}+\bar{v}_{\mathrm{F}}=-m_{2}[f(\varepsilon n)+2 g(n)]+\text { const }
\end{aligned}
$$

where: 


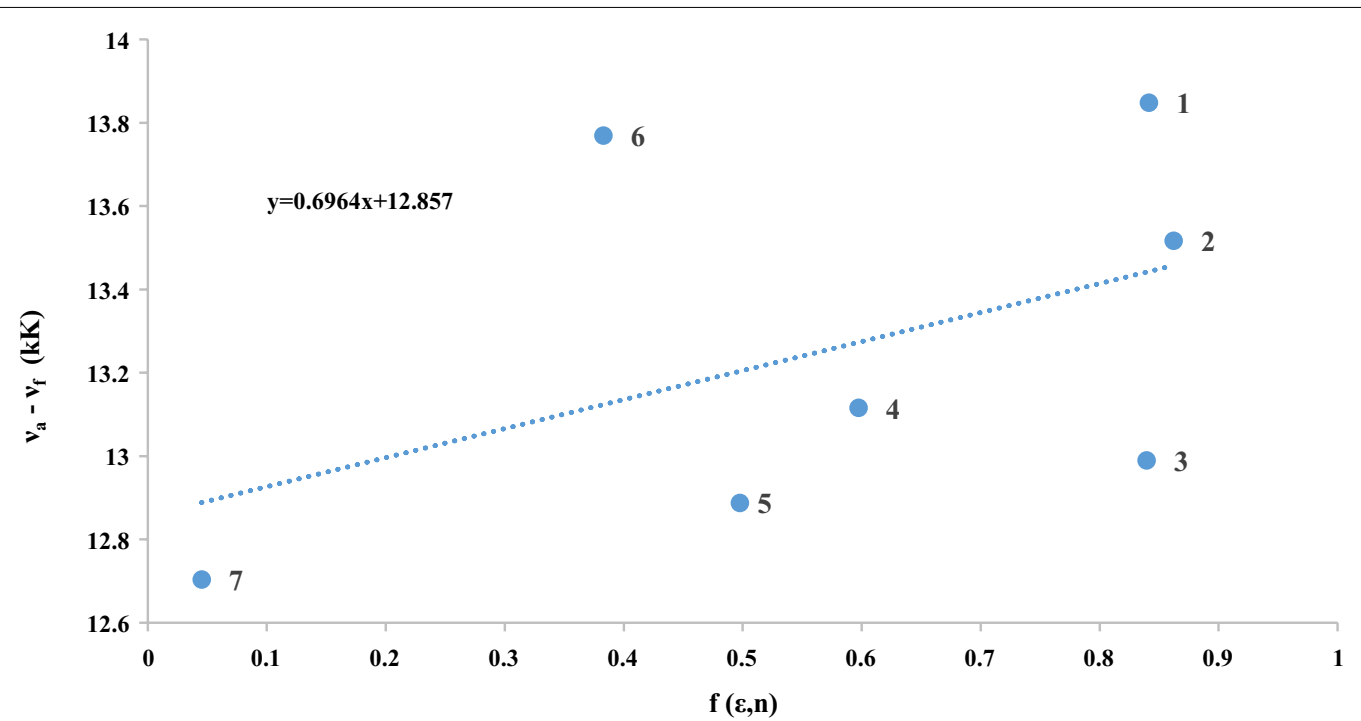

Fig. 3 Plot of $v_{a}-v_{f}(k K) v s . f(\varepsilon, n)$ for C-dots in the aprotic solvents: (1) DMSO, (2) Acetonitrile, (3) DMF, (4) DCM, (5) Acetic acid, (6) Diethyl ether, (7) Dioxane

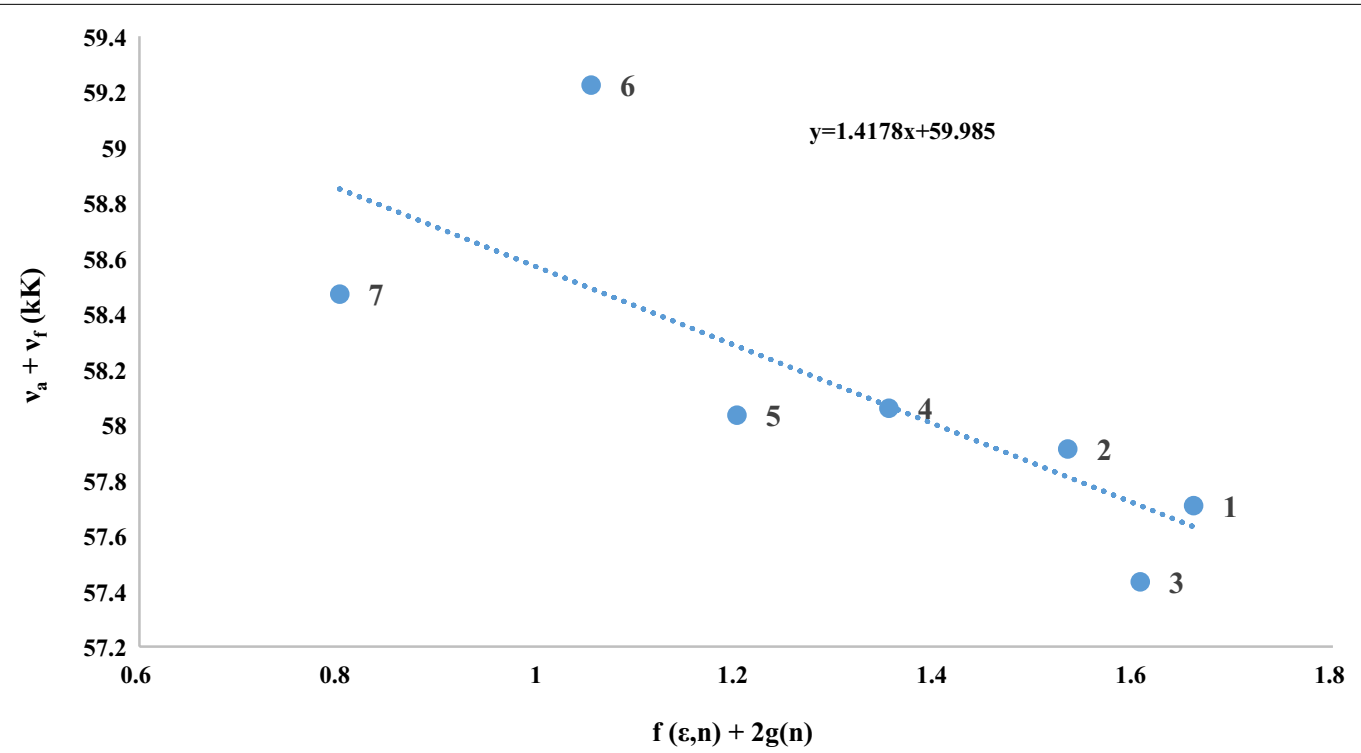

Fig. 4 Plot of $v_{a}+v_{f}(k K) v s . f(\varepsilon, n)+2 g(n)$ for CDs in the aprotic solvents: (1) DMSO, (2) Acetonitrile, (3) DMF, (4) DCM, (5) Acetic acid, (6) Diethyl ether, (7) Dioxane

$$
\begin{aligned}
& f(\varepsilon n)=\frac{2 n^{2}+1}{n^{2}+2}\left[\frac{\varepsilon-1}{2 \varepsilon+1}-\frac{\mathrm{n}^{2}-1}{2 \mathrm{n}^{2}+1}\right] \\
& g(n)=\frac{3}{2}\left[\frac{n^{4}-1}{\left(n^{2}+2\right)}\right]
\end{aligned}
$$

The parameters $m_{1}$ and $m_{2}$ can be determined from absorption and fluorescence band shifts $\left(\bar{v}_{\mathrm{A}}-\overline{\mathrm{v}}_{\mathrm{F}}\right)$ and $\left(\bar{v}_{\mathrm{A}}+\overline{\mathrm{v}}_{\mathrm{F}}\right)$ using the following equations:

$$
m_{1}=\frac{2\left(\mu_{e}-\mu_{g}\right)^{2}}{h c a^{3}}
$$




$$
m_{2}=\frac{2\left(\mu_{e}^{2}-\mu_{g}^{2}\right)}{h c a^{3}}
$$

where $h$ is Planck constant and $c$ is the velocity of light; $\mu_{\mathrm{e}}$ and $\mu_{\mathrm{g}}$ are the dipole moments in the ground and excited states; and $a$ is Onsager radius of the C-dots, which was obtained from the molecular model where the molar volume was calculated by $D F T-B 3 L Y P / 6-311++G(d, p)$ level of theory using Gaussian $0.3 \mathrm{~W}$ computer program. The value of the Onsager radius of the $\mathrm{C}$-dots is estimated to be $\mathrm{a}=3.97 \AA$.

Since the slope $m_{1}$ and $m_{2}$ from the graph in Figs. 3 and 4, fill in this value in Eqs. 8 and 9 we have:

$$
\begin{aligned}
& \mu_{g}=\frac{m_{2}-m_{1}}{2} \sqrt{\frac{h c a^{3}}{2 m_{1}}} \\
& \mu_{e}=\frac{m_{2}+m_{1}}{2} \sqrt{\frac{h c a^{3}}{2 m_{1}}}
\end{aligned}
$$

Thus, the ratio of dipole moments in excited state and ground state is given by:

$$
\mu_{e}=\frac{m_{1}+m_{2}}{m_{1}-m_{2}} \mu_{g}
$$

The value of Stokes shift varies between 12.70 and $13.84 \mathrm{kK}$. The values of the Stokes shifts are expressive of the charge transfer transition. The emission of C-dots dispersed in an aprotic solvent such as dioxane $(\varepsilon=2.3$, $\alpha=0)$ was recorded at $22.88 \mathrm{kK}$. While, in the aprotic solvents such as DMSO $(\varepsilon=47.27, \alpha=0)$, it was registered $21.92 \mathrm{kK}$. The larger dielectric constants result in a difference in Stokes shift of about $1.14 \mathrm{kK}$, indicating a chargetransfer transition. The surface external of C-dots can also donate a proton to the aprotic solvent. This interaction influences the emission, notwithstanding the strong hydrogen accepting capability of these solvents from DMSO to dioxane, which is compared by large $\beta$ KamletTaft parameters ( $\beta$ parameters listed in Table 1) $\beta=0.76$ and 0.37 , respectively.

The significant difference in the Stokes shift shows that the structural geometry of the excited state is different from the ground state. Table 2 shows the increase in Stokes shift with increasing aprotic solvent polarity, indicating an increase in dipole moment in the excited state. Spectral shifts $\left(\bar{v}_{\mathrm{A}}-\overline{\mathrm{v}}_{\mathrm{F}}\right)$ and $\left(\overline{\mathrm{v}}_{\mathrm{A}}+\overline{\mathrm{v}}_{\mathrm{F}}\right)$ of C-dots in polarity functions $f(\varepsilon, n)$ and $f(\varepsilon, n)+2 g(n)$ are illustrated in Figs. 3 and 4 . The slopes, intercepts and correlation coefficients of these best-fit lines are listed in Table 2. The slopes $m_{1}$ and $m_{2}$ of the fitted lines are presented in Table 3, the slopes of Figs. 3 and 4 were estimated to be $\mathrm{m}_{1}=696.4 \mathrm{~cm}^{-1}$ and $\mathrm{m}_{2}=1417.8 \mathrm{~cm}^{-1}$. The ground and excited state dipole moment were calculated using Eqs. (8) and (9) respectively, and the values are listed in Table 3. The values found for $\mu_{\mathrm{g}}=1.077 \mathrm{D}$, and $\mu_{\mathrm{e}}=3.157 \mathrm{D}$, as well as the change in the dipole moments $\left(\triangle \mu=\mu_{\mathrm{g}}-\mu_{\mathrm{e}}\right)$ is $1.077 \mathrm{D}$. The obtained dipole moment shows that the excited state dipole moment $\left(\mu_{\mathrm{e}}\right)$ is greater than ground-state dipole moment $\left(\mu_{\mathrm{g}}\right)$. It denotes that these $\mathrm{C}$-dots treated as dyes are more polar in the excited states.

\section{Effect of aprotic solvent on the absorbance and florescence spectra}

The typical fluorescence spectra and absorption spectra of $\mathrm{C}$-dots in different aprotic solvents are shown in Figs. 2 and 3 , respectively. The emission spectra of C-dots are broad, with shifts depending on the solvents. The large spectral shift is apparent in the fluorescence spectra compared to the absorption spectra. The smaller spectral shift in the absorption spectra than the emission spectra and the higher residence time for fluorescence indicate two phenomena. Firstly, the dipole moment of the excited state is greater than the ground state in all aprotic solvents studied. Secondly, the energy level of the first excited state, $S_{1}$, is stabilized compared to the ground state, $S_{0}$, by solvation with increasing the solvent polarity. These phenomena result in a redshift or bathochromic shift of the fluorescence.

The solvent effect was preserved within the outline of the linear solvation energy relationships (LSER) established by Kamlet-Taft [42] multivariate regression, in which each of specific and non-specific interactions has a linear contribution to the total solvation energy of solvent.

$$
E_{T}=A_{0}+S \pi^{*}+a \alpha+b \beta
$$

Here the coefficients $\pi^{\prime \prime}, \alpha$ and $\beta$ are the Kamelt-Taft solvatochromic parameters (KAT) which have been developed for scaling the dipolarity/polarizability,

Table 3 Regression fits to solvatochromic polarity scales for stokes shift of C-dots

\begin{tabular}{lllllll}
\hline Radius 'a' (A) $^{\prime}$ & $\boldsymbol{\mu}_{\mathrm{g}}(\mathrm{D})$ & $\boldsymbol{\mu}_{\mathrm{e}}(\mathrm{D})$ & $\Delta \boldsymbol{\mu}(\mathrm{D})$ & $\boldsymbol{\mu}_{\mathrm{e}} / \boldsymbol{\mu}_{\mathrm{g}}$ & $\mathrm{m}_{\mathbf{1}}\left(\mathrm{cm}^{-1}\right)$ & $\mathrm{m}_{\mathbf{2}}\left(\mathrm{cm}^{-1}\right)$ \\
\hline 3.97 & 1.077 & 3.157 & 2.08 & 2.931 & 696.4 & 1417.8 \\
\hline
\end{tabular}


Table 4 Linear correlations found by plotting $E_{T}$ versus $\pi^{*}$, $a$ and $\beta$ according to the KAT equation

\begin{tabular}{lllll}
\hline Sample & $\mathbf{A}_{\mathbf{0}}$ & $\mathbf{s}$ & $\mathbf{a}$ & $\mathbf{B}$ \\
\hline C-dots & 66.75 & -2.85 & 0.11 & -1.41 \\
\hline
\end{tabular}

Table 5 Percentage contribution of solvatochromic parameters in aprotic solvents

\begin{tabular}{llll}
\hline KAT parameters & $\mathbf{P}_{\pi^{*}}(\%)$ & $\mathbf{P}_{\mathbf{\alpha}}(\%)$ & $\mathbf{P}_{\boldsymbol{\beta}}(\%)$ \\
\hline C-dots & 65.21 & 2.51 & 32.26 \\
\hline
\end{tabular}

hydrogen-bond donor acidity and hydrogen-bond acceptor basicity of solvent, respectively $[36,43,44]$. The $A_{0}, a$, $b$ and $s$ are regression coefficients, quantity of the sensitivity of $E_{\mathrm{T}}$ values to the acidity, basicity and dipolarity/ polarizability, respectively. The fit parameters are represented in Table 4. The emission spectra energies were obtained by using Eq. 11 .

$$
E_{T}\left(\mathrm{kCal} . \mathrm{mol}^{-1}\right)=\frac{h c N_{A}}{\lambda_{\max }(\mathrm{nm})}=\frac{28591}{\lambda_{\max }(\mathrm{nm})}
$$

The molar electronic transition energy values, $\mathrm{E}_{\mathrm{T}}$, of the C-dots in solvents were calculated using Eq. 12. The results related to KAT parameters in fluorescence show that the primary distribution in C-dots is related to polarization interactions. Also, in the as-prepared C-dot, the $\pi^{\prime \prime}$ and $\beta$ sign are negative, indicating the ability to accept hydrogen bonding and polarization. For making the data in Table 4 reasonable and comparable, we have transformed the values in Table 5 into percentage contributions.

Also, in this study, the focus is on the solvatochromic effect of C-dots with solvents of low dielectric constants. Hence, the $\pi{ }^{\prime \prime}, \alpha$ and $\beta$ in aprotic solvents are shown in Fig. 5. As it is indicated in Fig. 5, linear dependence could have resulted from specific and non-specific interactions. The emission maximum $\mathrm{E}_{\mathrm{T}}$ diagram in $\pi^{*}$ for the range of aprotic solvents are shown in Fig. 5a. A linear dependence result indicates reasonable linearity with $\mathrm{r}=0.7$ between $\mathrm{E}_{\mathrm{T}}$ and $\pi^{*}$ in all aprotic solvents ranging from DMSO to dioxane. By plotting $\mathrm{E}_{\mathrm{T}}$ diagrams in terms of $\alpha$ and $\beta$, the results showed a poor linear dependence $(r=0.02)$ between $E_{T}$ and $\alpha$ as well as $E_{T}$ and $\beta(r=0.3)$ in the range of aprotic solvents. The reason for this significant deviation from the $\alpha$ parameter can be explained by the use of aprotic solvents that have low acidity, and in most cases, $\alpha$ was zero (Fig. $5 \mathrm{a}$ and b).

In contrast to our previous work, if we consider only the aprotic solvents, the results clearly show that the main contribution to solvatochromic is not related to the $\alpha$ scale of solvent HBD acidity and $\beta$ scale of solvent HBA basicity parameters of solvent. This relationship associates with parameter $\pi^{*}$, which shows the polarity/polarization of the solvents, and the measure of the stability of a charge or dipole moment with a dielectric effect [45]. The results show that non-specific interaction (dipoledipole) plays a significant role in solvatochromic of $n-\pi^{*}$ transition from edge band/edge states of C-dots [44].

The quantum yield of the C-dots dissolved in aprotic solvents was defined at an excitation wavelength of $350 \mathrm{~nm}$ using the following equation (Eq. 13)

$$
\mathrm{Q}_{\mathrm{CDs}}=\mathrm{Q}_{\mathrm{R}} \cdot \frac{\mathrm{I}_{\mathrm{CDs}}}{\mathrm{I}_{\mathrm{R}}} \cdot \frac{\mathrm{A}_{\mathrm{I}}}{\mathrm{A}_{\mathrm{CDs}}} \cdot \frac{\eta_{\mathrm{CDs}}^{2}}{\eta_{\mathrm{R}}^{2}}
$$

where $Q$ is the quantum yield, $I$ is the intensity of fluorescence spectra, $A$ is the absorbance at the excitation wavelength, and $\eta$ is the refractive index (1.33) of the solvent using quinine sulfate (quantum yield 0.5 ) in $0.1 \mathrm{M} \mathrm{H}_{2} \mathrm{SO}_{4}$ solution as the reference $[46,47]$. The subscripts ' $\mathrm{CDs}$ ' stands for carbon dots and ' $R$ ' for the reference are used in this equation. while the $\mathrm{C}$-dots was dissolved in water $(\eta=1.33)$, as the reference solution to keep their absorption at minimum ${ }^{<} 0.05$ by comparing the integrated fluorescence intensities using the Eq. 13 at excitation wavelength of $350 \mathrm{~nm}$ and the quantum yield was determinded. The quantum yield results calculated for C-dots are given in Table 1. According to the results, the highest amount of quantum yield among the studied aprotic solvents was obtained in diethyl ether (with a quantum yield of 0.53). This high quantum yield value can be attributed to the minimum value of AN in diethyl ether, among other aprotic solvents studied. To further explain this, it is assumed that the combination of other factors, such as the carbon core domain, affects emissions. However, solvatochromism deals with the effects of surface groups, and in the case of organic solvents, the effect of specific interactions such as hydrogen bond donors was minimal. Henceforth, if we limit our attention to the electron-donating and accepting characters of the constituents, the functional groups on the surface of C-dots containing $-\mathrm{NH}_{2}$ and $-\mathrm{OH}$ groups act as electron donors in their excited states. Thus, the surface energy traps are stabilized next to less polar solvents with lower acceptor number (AN) value and eventually promoted emission efficiency results $[29,49]$. At the practical level, further studies and research on the optical properties of C-dots, including quantum yield, are conserved in a wide range of solvents, and some of these solvents are potentially useful in biological applications. As the results illustrated in Table 1 the fluorescence efficiency in some of the solvent are significant. Nonetheless, they show no clear 


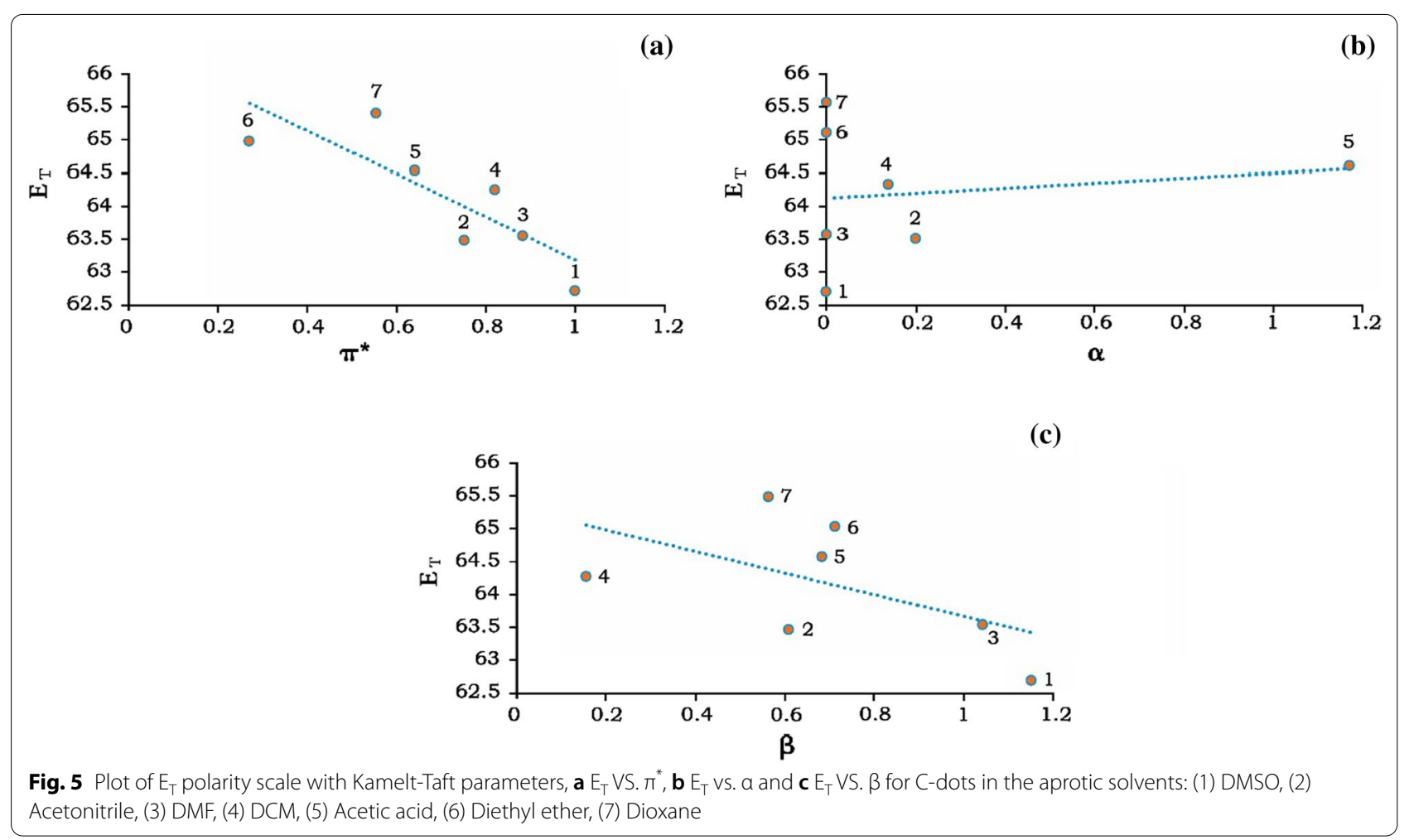

trend. Consistent with our previous study [35], it was shown that the solvent with greater AN (the higher electron-accepting character can be seen from their $\alpha$ values) was a more effective quencher.

\section{Conclusions}

In summary, in this research work, we dissolved C-dots in various aprotic solvents to explore the specific solvation effects. A different factor is expressed on C-dots solventsoluble interaction is generally controlled by the polarizability and basicity parameters. Studies were performed to calculate the dipole moment. The results showed that the excited state dipole moment is higher than the ground state. The results related to KAT parameters in fluorescence indicates the occurance of a bathochromic shift of the fluorescence.

One of the grand challenges in studying C-dots for biological applications and bio-imaging is to increase the duration and intensity of $\mathrm{C}$-dots fluorescence. Steps for more efficient use of $\mathrm{C}$-dots in this field prompted us to evaluate quantum yields, and the resulted values indicated significant improvements of C-dot's quantum yields in some aprotic solvents.

\section{Abbreviations}

C-dots: Carbon dots; PL: Photoluminescence; KAT: Kamelt-Taft; NaOH: Sodium hydroxide; DMSO: Dimethyl sulfoxide; DMF: Dimethylformamide; DCM:
Dichloromethane; FE-SEM: Field emission scanning electron microscopy; FT-IR: Fourier transform infrared; LSER: Linear solvation energy relationships; HBA: Hydrogen bond acceptor; HBD: Hydrogen bond donor.

\section{Acknowledgements}

The authors would like to acknowledge the Faculty of Advance Medical Sciences at Tabriz University of Medical Sciences and Faculty of Basic Sciences at Azarbaijan Shahid Madani University.

\section{Authors' contributions}

PMJ Conceptualization, methodology, validation, formal analysis, investigation, data Curation, Writing — original draft, Writing — review \& editing, software, visualization and was a major contributor in writing the manuscript; AA and RSA: Conceptualization, methodology, investigation, resources, data Curation, Writing —original draft, Writing — review \& editing, supervision, project administration; MPM: Conceptualization, methodology, validation, resources, Writing —original draft, Writing—review \& editing, supervision; KJG: Supervision, project administration, review \& editing. AA and PJ wrote the main manuscript text and MP prepared figures. All authors reviewed the manuscript.All authors read and approved the final manuscript.

\section{Funding}

Not applicable.

\section{Availability of data and materials}

All datasets generated or analyzed during the current study are included in this published article.

\section{Declarations}

Ethics approval and consent to participate Not applicable.

\section{Consent for publication}

Not applicable. 


\section{Competing interests}

The authors declare that there is no conflict of interest regarding the publication of this paper.

\section{Author details}

'Department of Chemistry, Faculty of Basic Sciences, Azarbaijan Shahid Madani University, 35 km Tabriz-Maraghe Road, P. O. Box 53714161, Tabriz, Iran. ${ }^{2}$ Department of Medical Biotechnology, Faculty of Advanced Medical Sciences, Tabriz University of Medical Sciences, Tabriz, Iran. ${ }^{3}$ Department of Medical Nanotechnology, Faculty of Advanced Medical Sciences, Tabriz University of Medical Sciences, Tabriz, Iran. ${ }^{4}$ Department of Physics, Faculty of Basic Sciences, Azarbaijan Shahid Madani University, 35 km Tabriz-Maraghe Road, Tabriz, Iran. ${ }^{5}$ Department of Medical Nanotechnology, Faculty of Medical Sciences, Tabriz University of Medical Sciences, Tabriz, Iran.

Received: 22 June 2021 Accepted: 15 September 2021

\section{Published online: 25 September 2021}

\section{References}

1. Wang $X$, Feng $Y$, Dong $P$, Huang J. A mini review on carbon quantum dots: preparation, properties, and electrocatalytic application. Front Chem. 2019:7:1-9.

2. Semeniuk M, Yi Z, Poursorkhabi V, Tjong J, Jaffer S, Lu Z-HH, et al. Future perspectives and review on organic carbon dots in electronic applications. ACS Nano. 2019;13:6224-55

3. Xiong H-F, An B-L, Zhang J-M, Yin C, Wang X-H, Wang J-H, Xu J-Q. Efficient one step synthesis of green carbon quantum dots catalyzed by tin oxide. Mater Today Commun. 2021;26:101762.

4. Li M, Chen T, Gooding JJ, Liu J. Review of carbon and graphene quantum dots for sensing. ACS Sens. 2019;4:1732-48.

5. Dong X, Liang W, Meziani MJ, Sun Y-P, Yang L. Carbon dots as potent antimicrobial agents. Theranostics. 2020;10:671.

6. Xu X, Ray R, Gu Y, Ploehn HJ, Gearheart L, Raker K, Scrivens WA. Electrophoretic analysis and purification of fluorescent single-walled carbon nanotube fragments. J Am Chem Soc. 2004;126:12736-7.

7. Wang B, Tang W, Lu H, Huang Z. Hydrothermal synthesis of ionic liquidcapped carbon quantum dots with high thermal stability and anion responsiveness. J Mater Sci. 2015;50:5411-8.

8. Jin X, Sun X, Chen G, Ding L, Li Y, Liu Z, Wang Z, Pan W, Hu C, Wang J. PHsensitive carbon dots for the visualization of regulation of intracellular $\mathrm{pH}$ inside living pathogenic fungal cells. Carbon. 2015;81:388-95

9. Hou Y, Lu Q, Deng J, Li H, Zhang Y. One-pot electrochemical synthesis of functionalized fluorescent carbon dots and their selective sensing for mercury ion. Anal Chim Acta. 2015:866:69-74.

10. Ye Y, Yang D, Chen H, Guo S, Yang Q, Chen L, Zhao H, Wang L. A highefficiency corrosion inhibitor of $\mathrm{N}$-doped citric acid-based carbon dots for mild steel in hydrochloric acid environment. J Hazard Mater. 2020:381:121019.

11. Kainth S, Maity B, Basu S. Deciphering the interaction of solvents with dual emissive carbon dots: a photoluminescence study and its response for different metal ions. Mater Sci Eng C. 2020;108:110443.

12. Mitra S, Chandra S, Kundu T, Banerjee R, Pramanik P, Goswami A. Rapid microwave synthesis of fluorescent hydrophobic carbon dots. RSC Adv. 2012;2:12129-31.

13. Li X, Wang H, Shimizu Y, Pyatenko A, Kawaguchi K, Koshizaki N. Preparation of carbon quantum dots with tunable photoluminescence by rapid laser passivation in ordinary organic solvents. Chem Commun 2010:47:932-4.

14. Shen C-L, Lou Q, Liu K-K, Dong L, Shan C-X. Chemiluminescent carbon dots: synthesis, properties, and applications. Nano Today. 2020;35:100954

15. Shen C-L, Lou Q, Lv C-F, Zheng G-S, Zang J-H, Jiang T-C, et al. Trigonal nitrogen activates high-brightness chemiluminescent carbon nanodots. ACS Mater Lett. 2021;3:826-37.

16. Shen C, Lou Q, Zang J, Liu K, Qu S, Dong L, et al. Near-infrared chemiluminescent carbon nanodots and their application in reactive oxygen species bioimaging. Adv Sci. 2020;7:1903525.

17. Hu S, Li X, Wang K, Wu Q, Zhang G, Liu X. Sensor array based on carbon dots for ATP-related physiological phosphates detecting and ATP hydrolysis monitoring. Sens Actuators B. 2020;310:127851.
18. Kashaninejad N, Yaghoobi M, Pourhassan-Moghaddam M, Bazaz SR, Jin D, Warkiani ME. Biological diagnosis based on microfluidics and nanotechnology. Nanotechnol Microfluid. 2020;211-38.

19. Li H, Yan X, Kong D, Jin R, Sun C, Du D, et al. Recent advances in carbon dots for bioimaging applications. Nanoscale Horizons. 2020:5:218-34.

20. Ehtesabi H, Hallaji Z, Nobar SN, Bagheri Z. Carbon dots with pH-responsive fluorescence: a review on synthesis and cell biological applications. Microchim Acta. 2020;187:1-18.

21. Gao N, Huang L, Li T, Song J, Hu H, Liu Y, et al. Application of carbon dots in dye-sensitized solar cells: a review. J Appl Polym Sci. 2020;137:48443.

22. Kumari R, Sahu SK. Effect of solvent-derived highly luminescent multicolor carbon dots for white-light-emitting diodes and water detection. Langmuir. 2020;36:5287-95.

23. Kou X, Jiang S, Park S-J, Meng L-Y. A review: recent advances in preparations and applications of heteroatom-doped carbon quantum dots. Dalton Trans. 2020;42:6915-38.

24. Kumar P, Bohidar HB. Observation of fluorescence from non-functionalized carbon nanoparticles and its solvent dependent spectroscopy. J Lumin. 2013;141:155-61.

25. Reichardt C, Welton T. Solvents and solvent effects in organic chemistry Hoboken: Wiley; 2011.

26. Kessler MA, Wolfbeis OS. New highly fluorescent ketocyanine polarity probes. Spectrochim Acta, Part A. 1991;47:187.

27. Suppan P. Invited review solvatochromic shifts: The influence of the medium on the energy of electronic states. J Photochem Photobiol, A. 1990;50:293-330

28. Pan D, Zhang J, Li Z, Wu C, Yan X, Wu M. Observation of pH-, solvent-, spin-, and excitation-dependent blue photoluminescence from carbon nanoparticles. Chem Commun. 2010;46:3681-3.

29. Mukherjee S, Prasad E, Chadha A. H-Bonding controls the emission properties of functionalized carbon nano-dots. Phys Chem Chem Phys. 2017;19:7288-96.

30. Lippert E. Dipolmoment und Elektronenstruktur von angeregten Molekülen. Zeitschrift für Naturforschung A. 1955;10:541-5.

31. von Lippert E. Spektroskopische Bestimmung des Dipolmomentes aromatischer Verbindungen im ersten angeregten Singulettzustand. Zeitschrift für Elektrochemie, Berichte der Bunsengesellschaft für physikalische Chemie. 1957:61:962-75.

32. Ravi M, Samanta A, Radhakrishnan TP. Excited state dipole moments from an efficient analysis of solvatochromic stokes shift data. J Phys Chem. 1994;98:9133-6.

33. Chamma A, Viallet P. Determination du moment dipolaire d'une molecule dans un etat excite singulet. CR Acad Sci Paris Ser C. 1970;270:1901-4.

34. der Kawski A. Wellenzahl von elecktronenbanden lumineszierenden moleküle. Acta Phys Polon. 1966;29:507-18.

35. Mohammad-Jafarieh P, Salamat-Ahangari R, Pourhassan-Moghaddam $M$, Akbarzadeh A. An insight into the solvatochromic and photophysical behaviours of biowaste-origin carbon nanodots. J Mol Liquids. 2021:336:116360.

36. Taft RW, Kamlet MJ. The solvatochromic comparison method. 2. The. Alpha.-scale of solvent hydrogen-bond donor (HBD) acidities. J Am Chem Soc. 1976;98:2886-94

37. Sahu S, Behera B, Maiti TK, Mohapatra S. Simple one-step synthesis of highly luminescent carbon dots from orange juice: application as excellent bio-imaging agents. Chem Commun. 2012:48:8835-7.

38. Bilot L, Kawski A. Zur theorie des einflusses von Lösungsmitteln auf die elektronenspektren der moleküle. Zeitschrift für Naturforschung A. 1962;17:621-7.

39. Kawski A, Kukliński B, Bojarski P. Dipole moment of aniline in the excited S1 state from thermochromic effect on electronic spectra. Chem Phys Lett. 2005;415:251-5.

40. Kawski A, Rabek JF. Progress in photochemistry and photophysics. Boca Raton, Boston. 1992;1-47.

41. Bakhshiev NG. Universal intermolecular interactions and their effect on the position of the electronic spectra of molecules in two-component solutions. VII. Theory (general case of an isotropic solution). Optics Spectrosc. 1964;16:446.

42. Taft RW, Abboud J-LM, Kamlet MJ, Abraham MH. Linear solvation energy relations. J Solut Chem. 1985;14:153-86. 
43. Kamlet MJ, Taft RW. The solvatochromic comparison method. I. The. Beta.scale of solvent hydrogen-bond acceptor (HBA) basicities. J Am Chem Soc. 1976;98:377-83.

44. Kamlet MJ, Abboud JL, Taft RW. The solvatochromic comparison method. 6. The.pi.* scale of solvent polarities. J Am Chem Soc. 1977;99:6027-38.

45. Kamlet MJ, Abboud JLM, Abraham MH, Taft RW. Linear solvation energy relationships. 23. A comprehensive collection of the solvatochromic parameters,. pi. ${ }^{*}$, alpha., and beta., and some methods for simplifying the generalized solvatochromic equation. J Org Chem. 1983:48:2877-87.

46. Ortega-Liebana MC, Hueso JL, Ferdousi S, Arenal R, Irusta S, Yeung KL, Santamaria J. Extraordinary sensitizing effect of co-doped carbon nanodots derived from mate herb: application to enhanced photocatalytic degradation of chlorinated wastewater compounds under visible light. Appl Catal B. 2017;218:68-79.
47. Shen J, Shang S, Chen X, Wang D, Cai Y. Facile synthesis of fluorescence carbon dots from sweet potato for $\mathrm{Fe} 3+$ sensing and cell imaging. Mater Sci Eng C. 2017;76:856-64.

48. Ramezani Z, Qorbanpour M, Rahbar N. Green synthesis of carbon quantum dots using quince fruit (Cydonia oblonga) powder as carbon precursor: application in cell imaging and As3+ determination. Colloids Surf A. 2018:549:58-66.

49. Shen C, Lou Q, Lv C, Zang J, Qu S, Dong L, Shan C. Bright and multicolor chemiluminescent carbon nanodots for advanced information encryption. Adv Sci. 2019;6:1802331.

\section{Publisher's Note}

Springer Nature remains neutral with regard to jurisdictional claims in published maps and institutional affiliations.
Ready to submit your research? Choose BMC and benefit from:

- fast, convenient online submission

- thorough peer review by experienced researchers in your field

- rapid publication on acceptance

- support for research data, including large and complex data types

- gold Open Access which fosters wider collaboration and increased citations

- maximum visibility for your research: over 100M website views per year

At BMC, research is always in progress.

Learn more biomedcentral.com/submissions 